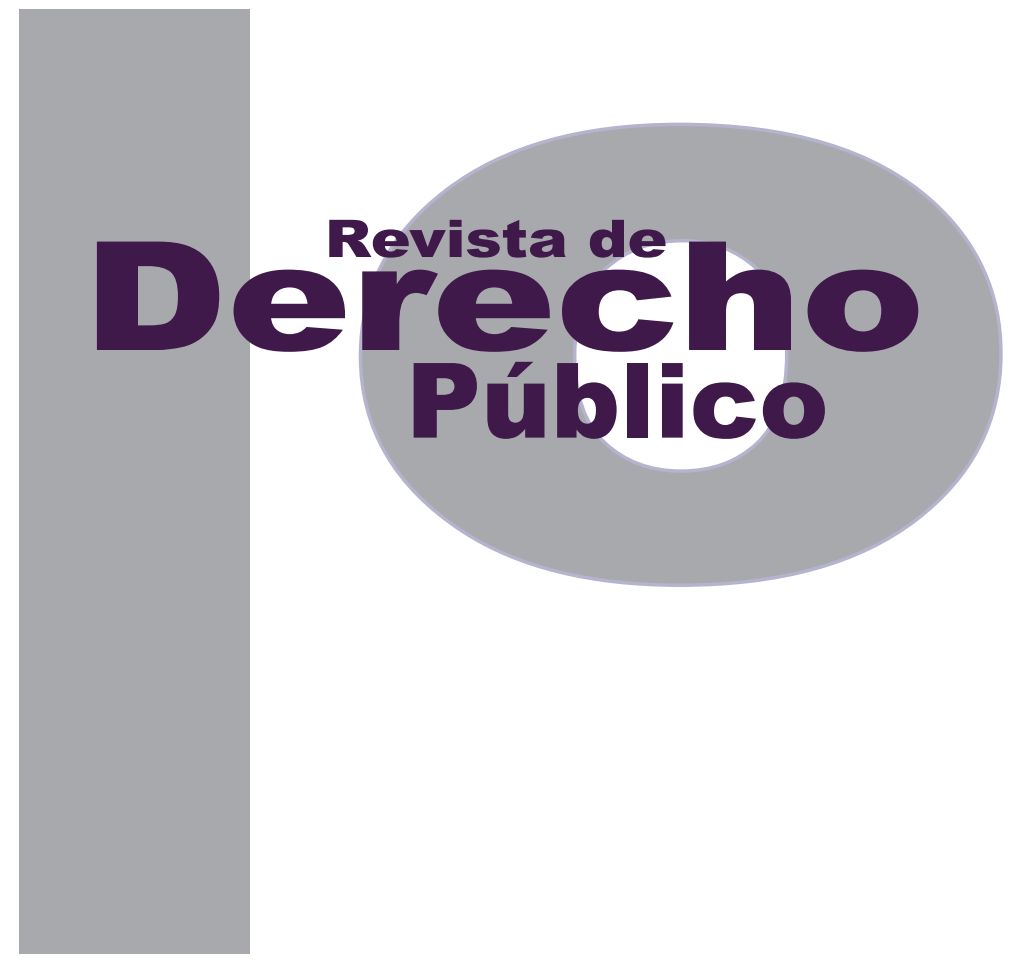

\title{
EFICACIA NORMATIVA EN MATERIA TRIBUTARIA
}

\author{
ELEONORA LOZANO RODRÍGUEZ \\ ANDRÉs Felipe RAMírez OCAMPO
}

Artículo de reflexión

DOI: http://dx.doi.org/10.15425/redepub.35.2015.11

Universidad de los Andes

Facultad de Derecho

Rev. derecho publico No.35

julio - diciembre de 2015. ISSN 1909-7778 


\section{Eficacia normativa en materia tributaria}

\section{Resumen}

El texto presenta la discusión sobre los diferentes tipos de eficacia (instrumental y simbólica) caracterizados por García Villegas (1993) y su aplicabilidad a la legislación tributaria colombiana. Para lograrlo describe la eficacia instrumental de las reformas tributarias clasificadas en endógenas y exógenas al PIB según la metodología de Romer y Romer (2010), y demuestra la poca o nula eficacia de este tipo que han exhibido estas normas en el período 1989-2015. Por último, analiza si esta "ineficacia" se debe a una simple ineptitud legislativa para producir los resultados deseados o si existen otros elementos que puedan ser considerados como eficacia simbólica ante este aparente fracaso.

Palabras clave: eficacia instrumental y simbólica, normativa tributaria colombiana (1989-2015).

\section{Regulatory effectivness in tax matters}

\section{Abstract}

This text presents a discussion of the different types of efficacy (instrumental and symbolic) characterized by Garcia Villegas (1993) and its applicability to the Colombian tax legislation. In doing so, this piece describes the instrumental efficacy of tax reforms classified as endogenous and exogenous to the GDP according to the methodology of Romer and Romer (2010), and shows little or no effectiveness of the instrumental efficacy of tax reforms between 1989-2015. FinaIly, this piece analyzes whether this "inefficiency" is due to a simple legislative ineptitude to produce the desired results or if there are other elements that could be considered effectively symbolic to this apparent failure.

Keywords: instrumental and symbolic efficacy, Colombian tax regulations (1989-2015).

\section{Eficácia normativa em matéria tributária}

\section{Resumo}

O texto apresenta a discussão sobre os diferentes tipos de eficácia (instrumental e simbólica) caracterizados por García Villegas (1993) e sua aplicabilidade à legislação tributária colombiana. Para isso, descreve a eficácia instrumental das reformas tributárias classificadas em endógenas e exógenas ao PIB segundo a metodologia de Romer e Romer (2010), e demonstra a pouca ou nula eficácia deste tipo que têm exibido estas normas no período de 1989-2015. Por último, analisa se esta "ineficácia" se deve a uma simples ineptidão legislativa para produzir os resultados desejados ou se existem outros elementos que possam ser considerados como eficácia simbólica ante este aparente fracasso.

Palavras-chave: eficácia instrumental e simbólica, normativa tributária colombiana (1989-2015). 


\title{
Eficacia normativa en materia tributaria*
}

\author{
Eleonora Lozano Rodríguez \\ Andrés Felipe Ramírez Ocampo
}

\section{SUMARIO}

Introducción - I. LOS TIPOS DE EFICACIA Y SU ADAPTABILIDAD A LA NORMATIVA TRIBUTARIA - A. Tipos de eficacia - B. Adaptabilidad del concepto a la norma tributaria - II. EL GASTO TRIBUTARIO Y LA PÉRDIDA DE EFICACIA INSTRUMENTAL - III. LA EFICACIA INSTRUMENTAL DE LAS REFORMAS TRIBUTARIAS EXÓGENAS AL PRODUCTO INTERNO BRUTO - IV. LA EFICACIA INSTRUMENTAL DE LAS REFORMAS TRIBUTARIAS ENDÓGENAS AL PRODUCTO INTERNO BRUTO - V. LA EFICACIA SIMBÓLICA DE LAS REFORMAS TRIBUTARIAS - VI. CONCLUSIÓN PRELIMINAR - Referencias.

Cómo citar este artículo: Lozano Rodríguez, E. y Ramírez Ocampo, A. F. (Diciembre, 2015). EFICACIA NORMATIVA EN MATERIA TRIBUTARIA. Revista de Derecho Público, 35. Universidad de los Andes (Colombia).

En él se presentan algunos de los resultados del proyecto de investigación interfacultades de la Universidad de los Andes (facultades de Derecho y Economía), ID 623, denominado: ¿Qué tan importante es la estabilidad jurídica del sistema tributario para el crecimiento?

** Abogada, economista, magíster en Economía y doctora en Derecho. Directora de la Maestría en Derecho y de la Especialización en Tributación de la Universidad de los Andes.

*** Abogado y economista, asistente graduado de la Facultad de Derecho de la Universidad de los Andes. 
Introducción

Este artículo tiene por objetivo analizar la eficacia instrumental y simbólica de las reformas tributarias ocurridas en Colombia en el período 1989-2015, haciendo especial énfasis en la ponderación entre modelos endógenos y exógenos al producto interno bruto en la correspondiente normativa expedida.

Para este efecto, el estudio se divide en cinco partes y unas conclusiones preliminares. En la primera se revisa alguna literatura referida a la eficacia instrumental y simbólica, y se acoplan estas categorías sociojurídicas a la ley tributaria. En la segunda se señala alguna normativa colombiana que genera gasto fiscal, sus principales características y su naturaleza, dadas las categorías anteriormente enunciadas. En la tercera se analiza la eficacia instrumental de las reformas tributarias exógenas al producto interno bruto (PIB) según Romer y Romer (2010). Luego se realiza un breve análisis sobre estas mismas categorías con respecto a las reformas endógenas al PIB, siguiendo también a los mencionados autores, para terminar con unas conclusiones relativas a su utilidad teórica, su aplicabilidad y la discusión de la hipótesis preliminar respecto al alcance y significado de posibles eficacias simbólicas derivadas del conjunto.

En el anterior marco se realiza un análisis jurídico de las exposiciones de motivos de las reformas tributarias en el período bajo estudio, así como de documentos de análisis económico del derecho tributario sobre la materia. ${ }^{1}$ A pesar de

\footnotetext{
1 Weisbach (2008) recoge en dos volúmenes los principales estudios
} en materia de análisis económico del derecho tributario. Para efec- que el hilo conductor es la diferenciación entre ambos tipos de eficacia, el lector también podrá tomar este documento como un referente respecto a los resultados de los esfuerzos de política pública por parte del gobierno en materia tributaria en los últimos 26 años, lo cual podrá señalar nuevas líneas de investigación que profundicen las conclusiones aquí alcanzadas.

\section{LOS TIPOS DE EFICACIA Y SU ADAPTABILIDAD A LA NORMATIVA TRIBUTARIA}

\section{A. Tipos de eficacia}

Según García Villegas (1993) existen dos tipos de eficacia dentro de los cuales se puede analizar la capacidad normativa de las leyes para lograr los resultados perseguidos: la eficacia simbólica y la eficacia instrumental. La eficacia instrumental examina la adecuación de los resultados de una norma tras su implementación, frente a los objetivos propuestos. Si la norma jurídica tiene la capacidad de producir los efectos deseados, entonces puede decirse que es instrumentalmente eficaz. Por el contrario, si se crea una norma que no produce resultado algu-

\footnotetext{
tos de comprender la intuición y problemáticas económicas detrás del gasto tributario se recomienda el del profesor de la Universidad de Harvard Stanley S. Surrey denominado "Tax Incentives as a Device for Implementing Government Policy: A Comparison with Direct Government Expenditures" incluido en la parte IV del volumen II, publicado en 1970 en Harvard Law Review, 83 (4), 705-38, donde concluye que los incentivos fiscales son generalmente inferiores a los subsidios directos como medio para la consecución de objetivos sociales, en la medida en que los incentivos son generalmente menos equitativos ya que benefician a las personas ubicadas en los tramos impositivos altos, y además son de más difícil desarrollo y administración por estar a cargo de los comités fiscales y agencias administrativas que tienen poca experiencia en la política social no tributaria. Sugiere, por lo tanto, una fuerte presunción en contra de su uso (pág. 705).
} 
no o produce resultados diferentes a los perseguidos, puede afirmarse que no es instrumentalmente eficaz. Esta categoría es definida por García Villegas de la siguiente forma:

Las normas jurídicas pueden ser instrumentos prácticos dirigidos a la acción. En este caso la existencia de una norma no se explica simplemente por su validez formal sino por su capacidad para producir un cierto comportamiento en los individuos destinatarios de la norma. Este es el poder de regulación propiamente jurídico, el mismo que ha sido atribuido por antonomasia al derecho en las obras de innumerables filósofos y sociólogos. (1993, pág. 88).

Por otro lado, la eficacia simbólica es el efecto de la norma considerada como símbolo, es decir, el mensaje detrás de una norma que puede o no ser efectiva en su aplicación y en el cumplimiento de los objetivos propuestos explícitamente, pero sí eficaz en términos de algunos otros objetivos no declarados, tales como la propaganda política, la apariencia de normalidad en coyunturas difíciles, servir como cortina de humo para distraer respecto a otro tipo de objetivos o como una simple forma de engordar estadísticas, entre otros. En palabras de García Villegas, "la eficacia simbólica debe ser entendida como una estrategia deliberada de las instituciones creadoras o aplicadoras del derecho que consiste en desconocer los objetivos normativos en beneficio de otros objetivos no declarados" (1993, pág. 92). Así, una norma simbólicamente eficaz es aquella que, independientemente de su eficacia instrumental, cumple con objetivos no declarados por el emisor. Un ejemplo podría ser un reglamento emitido para regular una materia determinada, que contuviera excepciones que lo hicieran virtualmente inaplicable. En principio, el legislador habría cumplido en el objetivo de regular esa materia y, por ende, dar a entender al público que está acatando sus funciones institucionales, así los fines propuestos en la exposición de motivos no se cumplan instrumentalmente. La norma de este ejemplo sería eficaz como símbolo, puesto que habría comunicado efectivamente el mensaje deseado (el buen funcionamiento de la institución y la respuesta a las necesidades legislativas de la población), pero ineficaz como instrumento. En este sentido, el legislador habría cumplido con el objetivo no declarado de entregar el mensaje de estabilidad, pero estaría a su vez desconociendo el objetivo normativo propuesto expresamente.

\section{B. Adaptabilidad del concepto a la norma tributaria}

La norma tributaria, a diferencia de aquellas de otros ámbitos jurídicos como el civil o el comercial, tiene características especiales que hacen que la eficacia simbólica, a primera vista, sea más difícil de implementar por el legislador. En primer lugar, y teniendo en cuenta el criterio individualista de la interpretación de las normas tributarias (Bravo Arteaga, 2009), su interpretación debe restringirse a la ley, dada su excepcionalidad, por restringir las libertades individuales y el derecho de propiedad de las personas, de tal manera que "sus efectos sean lo más reducidos que sea posible" (pág. 169). Sin embargo, no desconocemos la existencia de interpretaciones que van más allá de lo literal -interpre- 
tación exégeta- y que acuden a las finalidades de la norma -interpretación teleológica-, la extensión lógica de esta -interpretación sistemática-, su historia -interpretación histórica-, su sentido de justicia -interpretación por equidad-, los principios en tensión -ponderación de principios-, entre otras, que podrían llevar a resultados más allá de los taxativos de la norma (Lozano y Mendoza, 2008). Segundo, la norma tributaria tiene vigencias prolongadas al año fiscal siguiente a su promulgación, al menos en tributos de período, por lo que el efecto simbólico o instrumental de la normativa no necesariamente es inmediato. Es así como, por ejemplo, el recaudo producto de la normativa aprobada se da en varios períodos fiscales, lo que hace que los contribuyentes interpreten la normativa y aumenten o disminuyan su aporte dependiendo de qué tan explícitos y claros sean los objetivos de esta.

Sin embargo, la comunicación de símbolos a través de la producción legislativa no está necesariamente restringida a estas dos características especiales que, en nuestra opinión, pueden ser vulneradas fácilmente para encauzar objetivos ulteriores. Por ejemplo, las personas como contribuyentes son más sensibles a la afectación económica directa de un impuesto que a otro tipo de medidas, especialmente en el caso de Estados impopulares o percibidos como corruptos (Fjeldstad, 2006). De esta manera, empíricamente se ha demostrado que el cumplimiento tributario se ve afectado por factores como la destinación que se le dé a los recursos fiscales por parte del Estado o el mal manejo de estos (v. gr. corrupción), es decir, la otra arista de la política fiscal: el gasto público (Lozano y Tamayo, 2014).

Resalta también la literatura que la eficacia simbólica en sí misma no tiene por qué ser necesariamente perjudicial para un sistema jurídico determinado, siempre y cuando esté acompañada de eficacia instrumental; de lo contrario se está ante la presencia de la denominada inflación normativa, así como de una desacreditación de las instituciones ejecutoras y salvaguardas de la ley y sus objetivos. Por lo mismo, una norma propuesta y efectivamente promulgada únicamente persiguiendo la eficacia simbólica agranda el número de normas disponibles, pero no modifica el statu quo, lo cual desvirtúa la función legislativa y hace innecesariamente complejo el sistema.

La literatura también ha mostrado que caben consideraciones diferentes a especular respecto a los símbolos que querrían transmitirse con una norma determinada. En muchas ocasiones puede confundirse la simple ineptitud de las normas jurídicas con un intento deliberado de producir eficacia simbólica, sin descartar que esta pueda ser un resultado puramente accidental de la actuación del legislador. Es decir, la teoría de García Villegas (1993) contempla la posibilidad de que exista eficacia simbólica en las normas cuando simplemente no son exitosas, porque fueron creadas no con el objetivo de cambiar o modificar algo explícitamente (o por lo menos no con esto como objetivo principal), sino con el de crear un significado con el simple acto de legislar, sin que fuere relevante el contenido normativo producido. 
Otra posibilidad, que no desvirtúa la categoría de este autor pero que claramente también está contemplada, es que la norma tenga como objetivo el expresado en la exposición de motivos pero no se obtenga el resultado esperado. En el mundo de la normativa tributaria colombiana la evidencia indica que este caso es más la regla que la excepción. De esa manera, la brecha fiscal que se ha pretendido cerrar con casi la totalidad de reformas tributarias hechas entre 1989 y el 2015 continúa aumentando a ritmos mayores que el recaudo que cada una de ellas pretendía incrementar. Por lo anterior, el primer interrogante que nos hacemos es: ¿el fracaso constante del legislativo en cuanto a cerrar la brecha fiscal tiene explicación simplemente en deficiencias de la política pública o puede existir un rol que la eficacia simbólica haya jugado en este campo?

Para responder este interrogante es preciso, primero, analizar la eficacia instrumental de las reformas tributarias en el período 1989-2015, en conjunto con uno de los factores que más impide que se cierre la brecha: el incremento constante del gasto tributario. Posteriormente volveremos al análisis sobre la eficacia simbólica de las reformas tributarias, ya conceptualizada y medida la eficacia instrumental, para dejar planteadas algunas posibles hipótesis sobre las motivaciones detrás del fracaso estructural del recaudo en el país, como se evidenciará de este resultado, y en el cumplimiento de los objetivos propuestos en las reformas.

Como nota metodológica debemos aclarar que por la restricción en la información disponible hemos decidido analizar exclusivamente los gastos tributarios relativos a los dos tributos principales del país como porcentaje del PIB, esto es, algo más del $80 \%$ del recaudo tributario nacional por impuestos internos (Moller et al., 2012), ${ }^{2}$ es decir, el impuesto sobre la renta y el impuesto al valor agregado (IVA).

Cuadro 1. Impuestos sobre la renta y al valor agregado como porcentaje del recaudo interno (19952015p).

\begin{tabular}{|l|c|c|c|c|c|c|c|c|c|c|c|}
\hline \multicolumn{1}{|c|}{ Concepto } & $\mathbf{1 9 9 5}$ & $\mathbf{1 9 9 7}$ & $\mathbf{1 9 9 9}$ & $\mathbf{2 0 0 1}$ & $\mathbf{2 0 0 3}$ & $\mathbf{2 0 0 5}$ & $\mathbf{2 0 0 7}$ & $\mathbf{2 0 0 9}$ & $\mathbf{2 0 1 1}$ & $\mathbf{2 0 1 3}$ & $\mathbf{2 0 1 5 p}$ \\
\hline $\begin{array}{l}\text { Renta y } \\
\text { complementarios }\end{array}$ & $59.7 \%$ & $56.3 \%$ & $56 \%$ & $52.8 \%$ & $49.1 \%$ & $54.1 \%$ & $54.8 \%$ & $54.6 \%$ & $50.6 \%$ & $57.8 \%$ & $50.5 \%$ \\
\hline IVA interno & $38 . \%$ & $41.3 \%$ & $41.2 \%$ & $37.6 \%$ & $37.7 \%$ & $35.6 \%$ & $34 \%$ & $34.2 \%$ & $35.1 \%$ & $27 \%$ & $28 \%$ \\
\hline Total & $97.8 \%$ & $97.6 \%$ & $97.2 \%$ & $90.4 \%$ & $86.8 \%$ & $89.7 \%$ & $88.8 \%$ & $88.8 \%$ & $85.7 \%$ & $84.8 \%$ & $78.5 \%$ \\
\hline
\end{tabular}

Fuente: elaboración propia. Compilación de los marcos fiscales de mediano plazo.

2 También los marcos fiscales de mediano plazo cuantifican estos gastos tributarios. 


\section{EL GASTO TRIBUTARIO Y LA PÉRDIDA DE EFICACIA INSTRUMENTAL}

Existe la percepción generalizada de que nuestro sistema tributario es inequitativo, y que gran dosis de su inequidad se debe al excesivo gasto tributario ocasionado por múltiples beneficios tributarios que quizás otrora tuvieron una finalidad social o fueron simplemente establecidos por presiones políticas, pero que hoy deben ser eliminados.

En reciente diagnóstico sobre el tema, preparado por un equipo del Banco Mundial, dirigido por Lars Christian Moller, se concluye que en Colombia existe una preocupante tendencia creciente de los gastos tributarios, definidos estos últimos como las transferencias de recursos públicos que son llevadas a cabo mediante la reducción de las obligaciones tributarias - beneficio o incentivo tributario- con respecto de un marco tributario de referencia (benchmark) (Moller et al., 2012, pág. 25). Así, estas “disposiciones normativas o prácticas que reducen o difieren los pagos tributarios de un grupo de contribuyentes" (Moller et al., 2012), son gastos presupuestales con el objetivo de incentivar ciertos sectores o en general mantener y atraer nueva inversión doméstica y extranjera.

Según el mencionado diagnóstico:

Existen alrededor de 200 gastos tributarios (GTs) con distintos objetivos de política pública, en el impuesto sobre la renta y en el impuesto al valor agregado (IVA). Aparte de la pérdida recaudatoria que conllevan (estimada en alrededor de 25 billones de pesos) (...), los gastos tributarios pueden tener efectos indirectos y no deseados sobre la eficiencia económica y la equidad, aumentando la complejidad del sistema tributario. Adicionalmente, incrementan sus costos de administración y de cumplimiento, a la vez que propician nuevas formas de fraude y elusión. (Moller et al., 2012, pág. 1). [Cursivas añadidas].

Cifra anterior que corresponde a 9.615 millones usD y que no contempla los beneficios tributarios incluidos en la normativa para otros impuestos del orden nacional ni tampoco aquellos definidos por los concejos municipales y asambleas departamentales a nivel local.

Así, los regímenes especiales tributarios que incluyen gastos tributarios sobre estos dos impuestos (renta e IVA, que equivalen a un poco más de diez puntos porcentuales del PIB) han aumentado considerablemente desde comienzos de la década del 2000 hasta hoy. Según el estudio en comento, el número de usuarios de zonas francas ${ }^{3}$ creció de manera exponencial

3 Una zona franca, de acuerdo con Garay (2004, págs. 378-379), está definida según la ley colombiana de la siguiente forma: "Una zona franca es un establecimiento público con personería jurídica, autonomía administrativa y patrimonio independiente, adscrito al Ministerio de Comercio Exterior, cuyo objeto es la prestación de un servicio público sin ánimo de lucro a personas naturales o jurídicas nacionales o extranjeras, domiciliadas o no en el país, que introduzcan dentro del área mercancías o materias primas libres de gravamen [cursivas añadidas] para manufacturar $\mathrm{u}$ operar en ellas y bien exportar sus productos o importar al resto del territorio nacional bienes introducidos inicialmente en la zona, que en este caso, se someterán a las normas de conformidad con la legislación aduanera". De acuerdo con PROCOLOMBIA (2015), en general, los usuarios de zona franca cuentan con beneficios tributarios importantes: (i) si son usuarios antes de diciembre de 2012, cuentan con una tarifa de renta equivalente al $15 \%$, y si lo son después de esta fecha, también deben pagar el impuesto sobre la renta para la equidad (CREE); (ii) no se causan ni pagan tributos aduaneros (IVA y arancel para mercancías que se introduzcan a la zona franca desde el exterior; (iii) exención de IVA para materias primas, insumos y bienes terminados adquiridos en el territorio aduanero nacional; entre otros. 
del 2003 hasta el 2011, así como el número de gastos tributarios por año en el mismo período, incluyendo principalmente los siguientes: (i) exenciones y exclusiones en el IvA y (ii) rentas exentas y descuentos tributarios (Moller et al., 2012).

De esta manera, el sacrificio fiscal como porcentaje del PIB aumentó en $2 \%$, con un crecimiento inusitado del número de contratos de estabilidad jurídica ${ }^{4}$ que impiden la creación de nuevos recaudos sobre las partes contratantes.

En conclusión, según el citado estudio del Banco Mundial, Colombia es uno de los países del continente con mayor gasto tributario como porcentaje del PIB y, además, con el mayor sector de personas exento en el impuesto sobre la renta. También al revisar las estadísticas de recaudo para América Latina y el Caribe para el período 1990-2013 de la Organización para la Cooperación y el Desarrollo Económicos (OCDE, 2015), se observa que aún hay espacio fiscal para mayor carga contributiva en Colombia, pues para el 2013 el total de la recaudación tributaria como porcentaje del PIB fue del 20.1, cifra inferior al promedio para América Latina, ${ }^{5}$ que fue de 21.3 y más aún al 34.1 de la media de los países OCDE (pág. 56).

4 Sobre la insostenibilidad futura de los contratos de estabilidad jurídica en Colombia, Azuero, Guzmán y Trujillo (2011, pág. 1) advierten: "Ios CEs existen porque el Gobierno busca maximizar los niveles de inversión a corto plazo ofreciendo una estabilidad tributaria sabiendo que ésta no es sostenible hacia el futuro. (...) Además, puede generarse una divergencia entre la maximización del capital físico existente (propósito de un gobierno benevolente) y el incremento en el flujo de inversión nueva (objetivo de un gobierno que busca 'mostrar resultados')."
Esto no quiere decir que el gasto tributario es en sí una herramienta fallida de política pública. Así lo reconoce la OCDE (2010):

El gasto tributario tiende a funcionar mejor bajo ciertas condiciones, estas son: (1) cuando los costos de administración (y de cumplimiento) son más bajos; (2) cuando hay baja probabilidad de fraude y abuso; (3) cuando existe un rango amplio de selección por parte del contribuyente (preferencias privadas de ahorro pensional, por ejemplo) y cuando el uso de una agencia de gastos no sea apropiado, y (4) cuando se requiere medir la capacidad de pago por parte del contribuyente. (Citada por Moller et al., 2012).

Sin embargo, las anteriores características no concurren en el caso colombiano, por cuanto los costos de administración de los gastos tributarios son altos dado que existen barreras a la información empresarial y, además, posiciones dominantes de las grandes multinacionales respecto al poder político, así como la presencia de grupos de interés en los organismos de toma de decisiones (la denominada por los economistas "captura del regulador").

Adicionalmente, la probabilidad de fraude y abuso es alta debido a la complejidad y falta de claridad de la normativa tributaria colombiana; aunado esto a que los mecanismos disponibles de sanción e investigación del fraude no siguen aún las últimas directrices de la OCDE en materia de BEPS (base erosion and profit shifting), las cuales buscan precisamente reducir estos comportamientos indeseables. Además, la cláusula antiabuso, recientemente incorporada a la nor- 
mativa colombiana, por su compleja redacción conlleva múltiples interpretaciones y se torna casi inaplicable, aunque resulta un buen inicio en la discusión del abuso de las formas jurídicas en materia tributaria (Lozano y Tamayo, 2014). También, y con frecuencia, la concesión de regímenes tributarios especiales no obedece necesariamente a un análisis cuantitativo de capacidad de pago sino, de forma más frecuente, a la presión que sean capaces de ejercer los grupos de interés para que un determinado sector o industria pueda contar con beneficios de esta naturaleza (Brixi, 2004).

Haciendo uso del método de ingreso renunciado, ${ }^{6}$ el diagnóstico del Banco Mundial encontró que anualmente los gastos tributarios en Colombia, vigentes en 2012, equivalían al 1.56\% del PIB solo para el impuesto a la renta (Moller et al., 2012). Esto es más del 30\% del total recaudado por este concepto en el mismo año, donde además los beneficiarios son pocos. En cuanto al IVA, el marco fiscal de mediano plazo del año 2013 calculó que el gasto fiscal para el año 2012 ascendió a 14 billones de pesos, equivalente a cerca del 1.3\% del PIB. En total, Moller et al. (2012) estiman que el costo fiscal de los gastos tributarios agregados es de alrededor de $4,5 \%$ del PIB, el $80 \%$ del cual se concentra en los diez gastos tributarios más grandes. ${ }^{7}$ Importan-

$6 \quad$ Mide la pérdida de ingresos que se produce después de introducir un gasto tributario (ex post), suponiendo que no hay cambio de comportamiento en los contribuyentes.

7 Según Moller et al. (2012), en el impuesto sobre la renta los principales gastos tributarios son las exenciones para personas naturales, las deducciones y exenciones para personas jurídicas, los ingresos no constitutivos de renta o ganancia ocasional y el $25 \%$ del total de los pagos laborales. En cuanto al IVA los principales son las exenciones (por mucho el mayor gasto tributario en 14'305,499 miles de millones), la tasa cero y las devoluciones de dos puntos por tarjetas bancarias. te hacer notar que esta cifra es muy superior a lo recaudado a través del gravamen a los movimientos financieros (GMF) y otros impuestos, y en buena parte depende de unos pocos incentivos fiscales que corroen la base impositiva. ${ }^{8}$

Siguiendo la teoría neoclásica, y dado que los impuestos afectan el valor del capital, una reducción en estos sería una estrategia óptima para atraer inversión extranjera. Sin embargo, teóricamente el aumento de componentes tales como el empleo, la infraestructura, el ingreso disponible a través de recaudos producto del crecimiento económico para combatir la corrupción y la inseguridad, entre otros, también incrementan la demanda de inversión extranjera directa en los países en desarrollo.

De acuerdo con Roca (2010), en los países en desarrollo la evidencia empírica indica que a pesar de que la elasticidad de la oferta de inversión extranjera directa se ve alterada positivamente por una disminución en las tarifas impositivas, esto no resulta en un aumento del capital físico en los países donde se invierte, ni provee los resultados esperados en cuanto a empleo e infraestructura y al aumento en el ingreso del gobierno. Esto se debe principalmente

8 En el año 2006, Ayala se refirió a las renuncias, gastos o beneficios fiscales en Colombia, señalando las dificultades de medición de sus resultados no solo en relación con los recaudos fiscales sino en el cumplimiento de los objetivos perseguidos (pág. 40). Dentro de estos clasifica aquellos concedidos a las entidades de beneficio social, los de la Ley Páez, la deducción por compra de activos, la exención en venta de acciones, entre otros. Sobre el impacto macroeconómico de los beneficios tributarios al capital establecidos en el 2003, Hamann, Lozano y Mejía (2011) consideran que hay ganancias importantes en términos de bienestar, acumulación de capital y empleo al fijarlos de manera permanente; sin embargo, pueden generarse efectos negativos en el corto plazo en el empleo y el producto, lo cual dependerá de cómo el gobierno financie el déficit generado (pág. 1). 
a que la competencia por atraer la inversión extranjera desencadena una "carrera hacia el fondo" que impide el cumplimiento de los objetivos planteados con la medida, puesto que conduce a que los precios decrezcan progresivamente y con ellos el ingreso obtenido.

Adicionalmente, en la mayoría de los casos las preocupaciones de los inversionistas no son prioritariamente las altas tarifas impositivas, como llevaría a creer el comportamiento de la política pública de los países en desarrollo, sino los problemas en los factores institucionales no impositivos que, además, se combaten con un recaudo eficiente.

La carrera hacia el fondo desencadena entonces un círculo vicioso donde la decisión de invertir no se ve influenciada exclusivamente por los impuestos sino por factores como la estabilidad política, macroeconómica y jurídica, dejando las diferencias entre tarifas impositivas en un cuarto o quinto plano. A su vez, los países en desarrollo compiten por atraer la inversión aumentando los beneficios disponibles, dejando menos recursos para invertir en los factores de real influencia para el inversionista extranjero.

Al final, para los países en desarrollo se recomienda más establecer menos beneficios tributarios y concentrarse en consolidar el recaudo, para proveer las condiciones adecuadas pro fomento de la inversión extranjera directa, involucrando la formación efectiva de capital físico en un clima institucional adecuado para su reproducción (Roca, 2010). Esto tiene un corolario importante, y es que un monto equivalente a más de un tercio del recaudo actual se está perdiendo en gastos tributarios que no son benéficos en el largo plazo ni puede demostrarse que se creen por necesidades cuantificables de cada contribuyente potencial, sino por la influencia que estos detentan sobre las instituciones.

Aquí volvemos a nuestro interrogante respecto a la eficacia instrumental y simbólica de las reformas tributarias. Se han dado hasta el momento algunas luces sobre lo que implica el gasto tributario respecto al recaudo en Colombia, y los efectos potenciales que este tipo de política pública tiene sobre la economía del país en el largo plazo.

En cuanto a la eficacia instrumental, es casi imposible medir el efecto del gasto tributario sobre las variables macroeconómicas, objetivo más allá de simples cuantificaciones respecto a la elasticidad de la oferta de inversión extranjera directa. Pese a que puede cuantificarse el aumento o descenso de los ingresos de las compañías nacionales, esta información se encuentra bajo el secreto corporativo y su acceso está limitado a la administración tributaria. Además, aunque los costos involucrados pueden ser cuantificados $-\mathrm{y}$ de hecho deben serlo por ley-, ${ }^{9}$ los beneficios no son medibles ni observables directamente más allá del aumento

9 La Ley 788 de 2002 dispuso en su artículo 87 lo siguiente: "Transparencia Fiscal. Para efectos de la transparencia fiscal, el Gobierno Nacional presentará anualmente con el proyecto de Ley del Presupuesto de Rentas y Apropiaciones un informe detallado en el que se deberá evaluar y hacer explícito el impacto fiscal de los beneficios, así como su fuente de financiación, ya sea por aumento de ingresos o disminución del gasto." También la Ley 819 de 2003 establece que los marcos fiscales de mediano plazo deben contener una estimación del costo fiscal de las exenciones, deducciones o descuentos existentes en la legislación tributaria colombiana. 
en la inversión extranjera a lo largo de los años. En esta medida, podría pensarse que la normativa que introduce un gasto tributario tiene una alta eficacia instrumental, sin embargo no lo es tanto si se sopesan los efectos nocivos descritos por Roca (2010), que para el caso colombiano se materializan en el pobre crecimiento del recaudo y el incremento de impuestos en otros sectores a través de constantes reformas tributarias.

A continuación se analiza la eficacia de las últimas reformas tributarias orientadas a aumentar el recaudo y a hacer más eficiente la estructura tributaria del país, para compararla con los resultados posteriores observables.

\section{LA EFICACIA INSTRUMENTAL DE LAS REFORMAS TRIBUTARIAS EXÓGENAS AL PRODUCTO INTERNO BRUTO}

De acuerdo con la metodología propuesta por Romer y Romer (2010), los cambios en la normativa tributaria pueden clasificarse dentro de dos grandes categorías: exógenos y endógenos al PIB. En esencia, los cambios exógenos al PIB son aquellos efectuados sin estar motivados ni tener en cuenta factores que alteren el crecimiento normal de la economía, es decir, no son contracíclicos ni están pensados en el corto plazo. La característica definitiva de las reformas tributarias exógenas es que son producidas con miras a generar efectos en el largo plazo, ya sea por medio de modificaciones estructurales que permitan mejoras institucionales o por peque- ñas modificaciones con efectos macroeconómicos beneficiosos.

Por este motivo nuestras conclusiones contemplan ambas categorías, puesto que la eficacia instrumental de las reformas tributarias exógenas al PIB no puede ser medida con el mismo criterio aplicado a las reformas tributarias orientadas principalmente a contrarrestar el déficit y cerrar la brecha fiscal, esto es, las endógenas al PIB. Así, al revisar las exposiciones de motivos de las reformas, distinguiremos entre aquellas que no cuentan con ningún o tienen pocos elementos endógenos al PIB y las demás. ${ }^{10}$

10 En el año 2005 se publican dos estudios sobre la efectividad de las reformas tributarias cercanas a esa fecha, el de Clavijo y el de Sánchez y Espinosa. En el último se concluye que "si bien entre 1980 y 2003 hubo un aumento importante de los ingresos del gobierno, las reformas tributarias llevadas a cabo en los últimos 20 años no tuvieron efectos importantes sobre la productividad de los impuestos; teniendo en cuenta que los aumentos de productividad se dan por disminuciones en las exenciones y/o en la evasión, y que en muchos casos la productividad fue el factor con mayores efectos sobre la variación de los recaudos, una disminución de las exenciones y un mayor control de la evasión del sistema impositivo en general podría traer aumentos significativos en los recaudos, sin necesidad de recurrir a reformas que modifiquen las tarifas de los impuestos particulares" (pág. 76). 
Cuadro 2. Reformas con aspectos exógenos, exposición de motivos y resultados observables

\begin{tabular}{|c|c|c|}
\hline LEY & EXPOSICIÓN DE MOTIVOS & RESULTADOS A CINCO años \\
\hline LEY 49 DE 1990 & $\begin{array}{l}\text { La reforma de } 1990 \text { tenía en cuenta las primeras me- } \\
\text { didas encaminadas a abandonar el sistema de susti- } \\
\text { tución de importaciones y adentrarse en las reformas } \\
\text { que instalaría el gobierno de Gaviria, incluida la nueva } \\
\text { Carta Política. Esta reforma propendía por modifica- } \\
\text { ciones estructurales en el sistema de recaudo, en los } \\
\text { siguientes puntos principales: (1) mejorar la eficiencia } \\
\text { de la administración tributaria mediante la creación de } \\
\text { una nueva superintendencia y la modernización de los } \\
\text { sistemas de recaudo (cruces de bases de datos elec- } \\
\text { trónicas, planes de carrera para funcionarios y modi- } \\
\text { ficaciones administrativas que permitieran una mayor } \\
\text { autonomía del fisco); (2) simplificar el impuesto de } \\
\text { renta que venía funcionando desde la década del } 70 \text {, } \\
\text { reduciendo el número de declarantes y eliminando la } \\
\text { doble tributación por utilidades de sociedades cotiza- } \\
\text { das en bolsa; (3) realizar acuerdos de intercambio de } \\
\text { información tributaria con otros países; (4) exigir la } \\
\text { corrección de las declaraciones para los contribuyentes } \\
\text { con el fin de evitar la evasión; (5) aumentar el recaudo } \\
\text { de impuestos indirectos, especialmente el Iva, en dos } \\
\text { puntos porcentuales. El aumento estimado del recaudo } \\
\text { para el impuesto a la renta como proxy de la eficiencia } \\
\text { de estas medidas fue fijado así: } 2.6 \% \text { del piB para } 1991 \text {, } \\
5.3 \% \text { para } 1992,7.5 \% \text { para } 1993 \text { y } 9.7 \% \text { para } 1994 .\end{array}$ & $\begin{array}{l}\text { El impuesto a la renta presentó un recaudo } \\
\text { del 4,16\% como porcentaje del PIB para } \\
\text { 1994. La evasión creció en 3,2 puntos por- } \\
\text { centuales desde la instauración de la me- } \\
\text { dida, estimada para los impuestos de IVA } \\
\text { y renta. La superintendencia proyectada } \\
\text { para la administración tributaria nunca fue } \\
\text { creada, y las grandes reformas planteadas } \\
\text { para el organismo no tuvieron cabida } \\
\text { (Cárdenas y Mercer-Blackman, 2005). }\end{array}$ \\
\hline
\end{tabular}




\begin{tabular}{|c|c|c|}
\hline LEY 383 DE 1997 & $\begin{array}{l}\text { Una reforma tributaria curiosa por no haber sido pre- } \\
\text { sentada en las fechas usuales (en lugar de diciembre } \\
\text { esta fue radicada en julio). La Ley } 383 \text { concentró los es- } \\
\text { fuerzos del gobierno en combatir la evasión de impues- } \\
\text { tos y el contrabando. Para estos efectos, quiso instau- } \\
\text { rar las siguientes medidas: (1) exigir una "tarjeta fiscal" } \\
\text { para los operadores de computadores y máquinas reg- } \\
\text { istradoras, donde quedara constancia de las diversas } \\
\text { operaciones vinculadas a estos equipos; (2) consagrar } \\
\text { la posibilidad de efectuar visitas de fiscalización para } \\
\text { la verificación del cumplimiento de todos los impues- } \\
\text { tos nacionales, no únicamente el impuesto de timbre } \\
\text { como venía ocurriendo; (3) instaurar controles que } \\
\text { facilitaran la integración de la administración del re- } \\
\text { caudo tributario, aduanero y cambiario en una misma } \\
\text { entidad (DIAN); (4) darle la responsabilidad de verifi- } \\
\text { cación de la documentación de registro o licencia de } \\
\text { importación al IccE, para controlar el contrabando; (5) } \\
\text { aumentar la tasa de interés en mora por no pago de } \\
\text { impuestos a la más alta del mercado; (6) extender la } \\
\text { responsabilidad solidaria por deudas tributarias a los } \\
\text { socios de sociedades de personas y de capital siempre } \\
\text { que estos cuenten con un interés mayoritario en dichas } \\
\text { sociedades; (7) volver a penalizar el contrabando e in- } \\
\text { de retenciones de renta e Iva. }\end{array}$ & $\begin{array}{l}\text { En 1996, año anterior a la implantación } \\
\text { de la medida, la evasión fiscal para renta } \\
\text { e IVA fue equivalente al } 27,5 \% \text { (como pro- } \\
\text { porción del recaudo potencial). Para } 1999 \\
\text { este porcentaje aumentó a } 48,19 \% \text {, para } \\
\text { disminuir luego en } 2001 \text { a } 29,57 \% \text {, por- } \\
\text { centaje en todo caso mayor al existente } \\
\text { antes de la medida. La no consignación de } \\
\text { las retenciones en renta e IVA no fue pe- } \\
\text { nalizada, mientras que el contrabando sí. } \\
\text { (Echavarría, 2005). }\end{array}$ \\
\hline LEY 788 DE 2002 & $\begin{array}{l}\text { Esta reforma es reflejo directo de las propuestas de } \\
\text { campaña del primer período del presidente Uribe y, } \\
\text { a pesar de enfocarse fuertemente en la necesidad de } \\
\text { disminuir el déficit fiscal, modifica sustancialmente el- } \\
\text { ementos estructurales que no se corresponden con las } \\
\text { motivaciones de corto plazo características de refor- } \\
\text { mas endógenas al PIB. En síntesis, propone lo siguiente: } \\
\text { (1) penalizar la evasión de impuestos con penas máxi- } \\
\text { mas de cuatro años de cárcel; ( } 2 \text { ) reducir la tasa de in- } \\
\text { terés moratorio a tres puntos por debajo de la tasa de } \\
\text { usura. Los demás elementos hacen parte de reformas } \\
\text { endógenas al PIB, y por ende no fueron incluidos en el } \\
\text { análisis. }\end{array}$ & $\begin{array}{l}\text { A pesar de que la evasión no fue penaliza- } \\
\text { da, sus niveles sí fueron reducidos en los } \\
\text { años posteriores gracias a la efectiva im- } \\
\text { plementación del sistema MuIsCA, que hizo } \\
\text { más fácil perseguir a los infractores. Mien- } \\
\text { tras que el nivel de evasión para renta en } \\
2002 \text { era equivalente al 36\% del potencial } \\
\text { de recaudo, esta cifra disminuyó a } 30 \% \text { en } \\
2006 \text {. Esto se debe en parte a los esfuerzos } \\
\text { adelantados desde } 1997 \text { para la consoli- } \\
\text { dación efectiva de las bases de datos del } \\
\text { organismo (Parra y Patiño, 2010). }\end{array}$ \\
\hline LEY 818 DE 2003 & Gasto tributario (exención de IVA para la panela). & Ver sección anterior. \\
\hline LEY 939 DE 2004 & $\begin{array}{l}\text { Gasto tributario (exención de IVA para la panela, bio- } \\
\text { diesel y otros cultivos relacionados). }\end{array}$ & Ver sección anterior. \\
\hline
\end{tabular}




\begin{tabular}{|c|c|c|}
\hline $\begin{array}{l}\text { LEY } 1004 \text { DE } \\
2005\end{array}$ & $\begin{array}{l}\text { Gasto tributario. Se propone adicionalmente con esta } \\
\text { medida, a finales del primer cuatrienio del presidente } \\
\text { Uribe, la eliminación del impuesto de remesas junto } \\
\text { con modificaciones a los descuentos del IVA relaciona- } \\
\text { dos con este tributo. }\end{array}$ & $\begin{array}{l}\text { Ninguna de las propuestas más allá del } \\
\text { gasto tributario, encaminado a aumentar } \\
\text { el alcance y duración de las zonas francas } \\
\text { en Colombia, fue aprobada. }\end{array}$ \\
\hline $\begin{array}{l}\text { LEY } 1379 \text { DE } \\
2010\end{array}$ & $\begin{array}{l}\text { Gasto tributario (exención de impuesto a la renta para } \\
\text { todas las donaciones relacionadas con el financiamien- } \\
\text { to de la Red Nacional de Bibliotecas). }\end{array}$ & Ver sección anterior. \\
\hline $\begin{array}{l}\text { LEY } 1430 \text { DE } \\
2010\end{array}$ & $\begin{array}{l}\text { Como complemento a la ley de primer empleo, esta } \\
\text { norma incluyó cambios estructurales a largo plazo para } \\
\text { mejorar el sistema de recaudo y hacerle frente a la eva- } \\
\text { sión, así como fomentar la formación. Entre otras, las } \\
\text { medidas propuestas incluyeron lo siguiente: (1) "la in- } \\
\text { formación que deben aportar los contribuyentes para } \\
\text { efectos del control tributario no está limitada a lo que } \\
\text { previamente ha definido la ley como necesario para el } \\
\text { ejercicio de la acción fiscalizadora, sino que se amplía } \\
\text { de acuerdo a la dinámica de los procesos económicos } \\
\text { y a los cambios de enfoque de la auditoría", ( } 2 \text { ) dis- } \\
\text { minuir y simplificar los procedimientos requeridos para } \\
\text { cumplir con las obligaciones impositivas nacionales, } \\
\text { mediante mecanismos como la exención de declara- } \\
\text { ción de renta para agentes retenedores que no hayan } \\
\text { efectuado retenciones en el período gravable, incen- } \\
\text { tivar la bancarización, y que ciertos contribuyentes } \\
\text { efectúen la retención a través de entidades financieras, } \\
\text { entre otras. }\end{array}$ & $\begin{array}{l}\text { En los cinco años posteriores a esta medida } \\
\text { y sus complementarias, el desempleo de- } \\
\text { scendió a cifras de un solo dígito, y el em- } \\
\text { pleo formal aumentó en un promedio de } \\
5,2 \% \text { anual entre } 2010 \text { y } 2015 \text {. }\end{array}$ \\
\hline
\end{tabular}




\begin{tabular}{|c|c|c|}
\hline $\begin{array}{l}\text { LEY } 1607 \text { DE } \\
2012\end{array}$ & $\begin{array}{l}\text { Esta reforma pretendía reducir la desigualdad y generar } \\
\text { empleo, mejorando la distribución de las cargas tribu- } \\
\text { tarias y haciendo a las empresas más competitivas. Asi- } \\
\text { mismo, establecer nuevos mecanismos para combatir } \\
\text { la elusión y la evasión tributaria. Concretamente, los } \\
\text { cambios contenidos en el articulado se concentran en } \\
\text { lo siguiente: (i) hacer el impuesto a la renta de personas } \\
\text { naturales más progresivo, eliminando los factores que } \\
\text { hacían más complejo el pago por parte de las personas } \\
\text { con menores ingresos; (ii) la introducción del ıMAN, que } \\
\text { permite disminuir los impuestos para los segmentos de } \\
\text { menos ingresos, que personas con ingresos mensu- } \\
\text { ales de menos de \$2.3 millones no paguen impuesto } \\
\text { de renta, y que los de mayores ingresos: personas que } \\
\text { ganan más de \$25 millones mensuales, paguen como } \\
\text { mínimo un } 15 \% \text {; (iii) la introducción del IMAS, que per- } \\
\text { mite elaborar declaraciones de renta simplificadas a las } \\
\text { personas que devenguen menos de \$240 millones de } \\
\text { pesos anuales, por el pago de una prima; (iii) la cre- } \\
\text { ación del cREE que no tiene en cuenta las nóminas de } \\
\text { las empresas sino la utilidad devengada en el período } \\
\text { gravable, para financiar principalmente al IcBF y al SENA; } \\
\text { (iv) modificaciones al IVA y al impuesto al consumo, (vi) } \\
\text { modificación de la tarifa por ganancia ocasional y (vii) } \\
\text { creación de nuevas normas antievasión y antielusión } \\
\text { que permitan un combate efectivo por parte de la DıAN } \\
\text { a estas conductas. }\end{array}$ & $\begin{array}{l}\text { El desempleo disminuyó a cifras de un solo } \\
\text { dígito entre } 2013 \text { y } 2014 \text {. Adicionalmente, } \\
\text { la administración tributaria cumplió sus } \\
\text { metas de recaudo en un } 96 \% \text {. Sin embar- } \\
\text { go, según Ayala (2006), en informe para } \\
\text { la Agencia Nacional de Infraestructura, se } \\
\text { identifica lo siguiente: "a pesar de las bue- } \\
\text { nas intenciones de mejorar en equidad (a } \\
\text { través del IMAN) y de promover la formal- } \\
\text { ización laboral mediante del desmonte de } \\
\text { 13,5\% puntos de parafiscalidad-laboral } \\
\text { (sustituyéndolos por el cREE), dicha refor- } \\
\text { ma ha resultado compleja de implementar } \\
\text { y denota bastante improvisación a la hora } \\
\text { de sus contradictorios y farragosos decre- } \\
\text { tos reglamentarios" (Ayala, 2006). }\end{array}$ \\
\hline
\end{tabular}

Fuente: elaboración propia con base en Lewin (2007) y las exposiciones de motivos de las reformas en mención.

Nota: no se incluye la última reforma tributaria, Ley 1739 de 2014, entre otras, por no ser exógena al PIB, en la medida en que fue diseñada para aumentar el recaudo por desfinanciación del presupuesto. 


\section{LA EFICACIA INSTRUMENTAL DE LAS REFORMAS TRIBUTARIAS ENDÓGENAS AL PRODUCTO INTERNO}

BRUTO

Aquí el análisis es más simple, en la medida en que la gran mayoría de las 0,48 reformas tributarias promedio anuales que Colombia ha soportado entre 1989 y 2015 son por defecto endógenas al PIB. De esa manera, a lo largo de estos 26 años el gobierno central se ha concentrado principalmente en un objetivo de política fiscal, cual es aumentar el recaudo de forma suficiente para compensar el gasto.

Sin embargo, combatir el déficit ha resultado ser sumamente difícil en la práctica. Como lo demuestra el gráfico 1, el panorama para Colombia no ha sido pacífico en relación con la distancia entre recaudo (ingresos) y gasto, a pesar de las constantes reformas a la normativa tributaria.

Gráfico 1. Evolución de ingresos y gastos públi$\cos (1994-2014)$

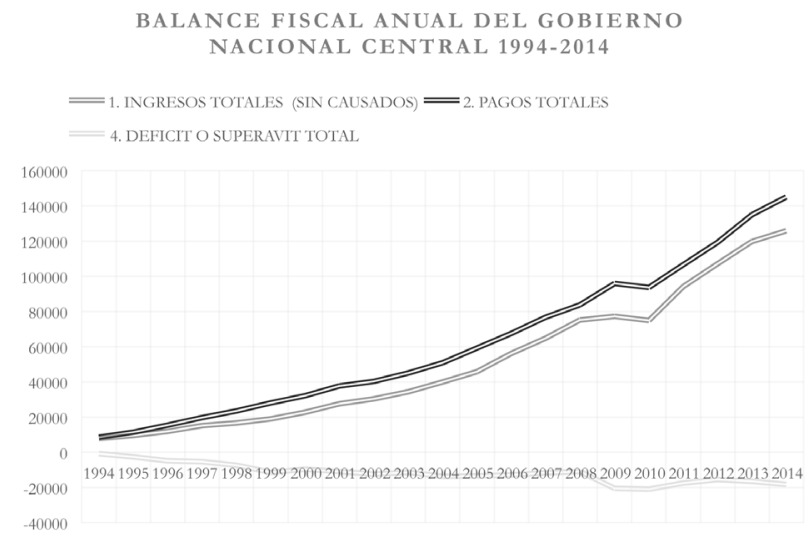

Fuente: elaboración propia. Datos del Ministerio de Hacienda y Crédito Público (MHCP): Balance fiscal anual del gobierno nacional central, 2014.
En el 2013 el déficit fiscal del país ascendía al $2,4 \%$ del PIB. A pesar de que la meta de déficit fiscal de 2014 se cumplió, con un déficit equivalente a $2,41 \%$ del PIB, este porcentaje podría aumentar para el 2015 dada la crisis desatada por la caída en los precios del petróleo, situándolo en alrededor de 3\% del PIB, pero dada la regla fiscal (L. 1473 de 2011, art. 5) ${ }^{11}$ deberá permanecer en el anterior nivel.

Como se puede observar, y a pesar de estar en vigor la regla fiscal, el recaudo aumenta pero de igual forma lo hace el gasto. Esto implica que a pesar de que las reformas tributarias endógenas al PIB tienen un cierto grado de eficacia instrumental (después de todo, los ingresos aumentan), el recaudo no es suficiente para superar el gasto del gobierno que crece más rápidamente. Así, una regresión lineal simple, como se muestra en el gráfico 2, indica que el déficit fiscal aumenta con una pendiente negativa de 1.01 billones de pesos por año.

11 "Artículo $5^{\circ}$. Regla Fiscal. El gasto estructural no podrá superar al ingreso estructural, en un monto que exceda la meta anual de balance estructural establecido. El déficit estructural del Gobierno Nacional Central no será mayor a $1 \%$ del PIB a partir del año 2022. Parágrafo transitorio. El Gobierno Nacional seguirá una senda decreciente anual del déficit en el balance fiscal estructural, que le permita alcanzar un déficit estructural de $2,3 \%$ del PIB o menos en 2014 , de $1.9 \%$ del PIB o menos en 2018 y de $1.0 \%$ del PIB o menos en 2022." 
Gráfico 2. Crecimiento del déficit (1994-2014)

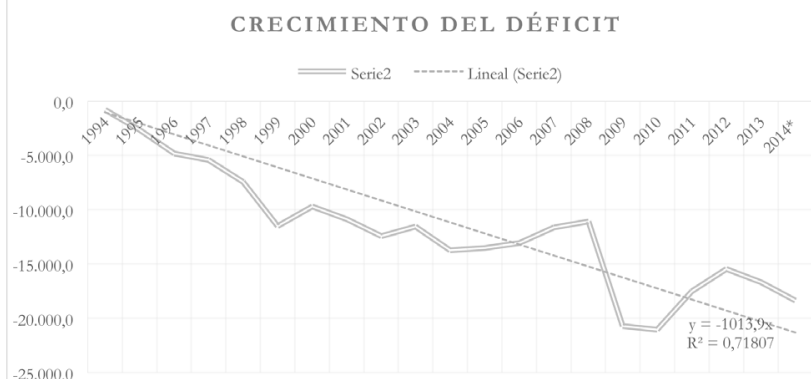

Fuente: elaboración propia. Datos del MHCP: Balance fiscal anual del gobierno nacional central, 2014.

En últimas el objetivo principal de estas reformas, que es subsanar el déficit fiscal, nunca se ha cumplido. De esa manera, pese a los esfuerzos por aumentar la base gravable, crear impuestos nuevos, cambiar, tergiversar, reemplazar y modificar de diferentes maneras el hecho gravable, y demás acrobacias del legislativo, ha sido imposible que las reformas tributarias en Colombia eliminen la brecha fiscal y permitan unas finanzas sanas y robustas. La anterior situación se torna aún más preocupante en una situación eventual de posconflicto, donde más bienes públicos habrá que proveerse y resultará un mayor gasto público en virtud de los acuerdos de La Habana (Lozano, en prensa).

En definitiva, la pregunta respecto a la eficacia instrumental parece relativamente clara en este campo, por cuanto el legislativo emite reformas que están principalmente orientadas a desvirtuar los efectos negativos de alguna circunstancia que altera la normalidad del recaudo (crisis financiera, crisis mundial, conflicto, posconflicto), pero ninguna de ellas logra a cabalidad el objetivo esperado de cerrar efectivamente la brecha fiscal. A pesar de que milagrosamente los presupuestos se ejecutan y parte de los deberes del gobierno se cumplen, cada año la deuda crece y los objetivos últimos del Estado social de derecho resultan más difíciles de alcanzar.

\section{LA EFICACIA SIMBÓLICA DE LAS REFORMAS TRIBUTARIAS}

Aumentar los impuestos es políticamente impopular. Tanto los sectores más ricos de la sociedad como los más pobres se resisten a la medida, la economía sufre pérdidas irrecuperables de eficiencia y la corrupción termina con una parte importante de los recursos que se consiguieron gracias a ese sacrificio. El creador de política pública que considere aumentar los impuestos a través de una reforma tiene que ser consciente, al menos, de que el costo político necesario para llevarla a acabo es importante, y que los retornos esperados deben ser sustanciales. Adicionalmente, en países como el nuestro, existen cada vez más controles a la creación de impuestos (en esencia, en virtud del principio de legalidad), y se busca la transparencia de los objetivos perseguidos.

Es fácil pensar que los lamentables resultados de la administración tributaria desde 1989 hasta hoy sean fruto únicamente de la ineptitud de las reformas planteadas y, en consecuencia, del sistema legislativo. Esta conclusión simplemente desconoce las complicadas redes involucradas en los intereses de financiación del Estado y olvida otras realidades que necesariamente deben ser consideradas. El Gobierno, en la gran 
mayoría de las reformas, propone legislación para aumentar el recaudo. Es así como los economistas más notables del país son contratados para dirigir la cartera de Hacienda y cada uno propone una aparente "reforma salvadora".

La panacea del cúmulo de reformas es solo un paliativo temporal a los problemas del país, pero cumple con su efecto simbólico. Así, los gobiernos reformadores en materia tributaria están dando un signaling importante a los consumidores de sus servicios, y a pesar del costo político involucrado en el aumento de los impuestos consideran que es necesario, y elaboran las reformas siempre estableciendo en detalle en las exposiciones de motivos los sectores de la población que van a sufrirlas, y cuáles son los beneficios obtenidos que van a compensar la balanza de logros y fracasos.

Por su parte, el gasto tributario también juega su rol. El valor de la inversión extranjera es inmune a la mayoría de las disposiciones tributarias, ya sea a través de contratos de estabilidad jurídica, amparándose en los beneficios de las zonas francas $u$ otros incentivos tributarios. Con estos últimos la inversión extranjera directa es atraída a uno de los países con las tasas impositivas de renta más altas del continente para personas jurídicas, pero el efecto simbólico está cumplido y el gobierno ha realizado los sacrificios necesarios a su popularidad aumentando la carga que sufre el contribuyente para mantener al Estado de derecho. De esa manera, los beneficios no pueden verse ni medirse, pero la situación es conveniente para las dos partes principales del contrato.
Mientras tanto, el debate por hacer reformas tributarias equitativas y progresivas existe apenas en la teoría, pero rara vez se implementa en la práctica. Coincidencialmente, los impuestos más fáciles de administrar son aquellos que por su naturaleza indirecta son transversales a la totalidad de la población sin importar su capacidad contributiva.

El simbolismo tributario es entonces una constante racha de modificaciones que producen el efecto de tranquilidad pasajera respecto al rumbo de las finanzas públicas y el futuro del Estado social de derecho. Al terminar las vigencias fiscales se hace uso de otros símbolos para indicar que un cambio superior es necesario, olvidando casi por completo el fracaso de las modificaciones anteriores. La simbología tributaria se expresa entonces en temporadas (ciclos) y podría pensarse que se ha convertido en un componente estructural y de política de los ciclos económicos del país. La ineficacia instrumental se ve entonces acoplada a la eficacia simbólica tributaria, que permite mantener en el tiempo las reformas coyunturales y justificar la escasez de reformas tributarias estructurales y orientadas a largo plazo.

\section{CONCLUSIÓN PRELIMINAR}

En este artículo nos hemos referido a la evolución de la política tributaria en los últimos años, analizando uno de sus principales componentes: el gasto tributario. También hemos revisado intuitivamente los efectos de dicha política en el producto interno bruto. 
Del análisis se concluye que la política pública tributaria en Colombia no es eficaz como instrumento fiscal. Esto tiene implicaciones importantes, puesto que la proliferación legislativa en materia tributaria indicaría un esfuerzo constante del legislativo por modificar las instituciones en la materia, cuando la realidad que se evidencia en este estudio es contraria a esta intuición: la proliferación legislativa en materia tributaria obedece en una proporción mucho mayor a modificaciones de corto plazo por choques presupuestales negativos que a reformas orientadas a mejorar el recaudo y hacerlo más eficiente. En términos de técnica fiscal, la existencia y cuantía de los gastos tributarios no puede considerarse una herramienta de largo plazo para aumentar el recaudo, puesto que, como se demostró, tiene el efecto contrario frente al desarrollo económico. Esto implica que aunado a la desproporción entre las reformas endógenas y exógenas al producto interno bruto, el sistema se encuentra desbalanceado por la existencia excesiva de gastos tributarios. En este sentido, las recomendaciones que hemos encontrado son muy claras. La política pública orientada a la manipulación macroeconómica de ciertos sectores, a través de incentivos de diversos tipos, no funciona en contextos de instituciones débiles donde las posibilidades de eludir o evadir son altas y los costos de hacerlo son bajos. En ese orden de ideas, el recaudo se ve afectado considerablemente y la ganancia observable se mide únicamente en econometrías apenas significativas, que desafortunadamente distan de conclusiones claras.
En cuanto a reformas tributarias exógenas al producto interno bruto se refiere, nuestra investigación indica que las reformas enteramente exógenas al producto son pocas, muchas de ellas confundiéndose con gastos tributarios de distintos tipos. La lucha contra la evasión, adicionalmente, es poco eficaz instrumentalmente; y sus efectos solo se reflejan en el largo plazo, sin que pueda decirse lo mismo de los esfuerzos por modernizar el recaudo, por ampliar la base de contribuyentes y por darle al país la capacidad necesaria para perseguir el ingreso teórico con el que se cuenta en muchas instancias presupuestales.

Aunado a lo anterior, los resultados finales de las reformas abarcan un porcentaje pequeño de lo previsto en las exposiciones de motivos. Lo anterior implica que en las pocas oportunidades en las que el legislativo ha efectuado modificaciones a las instituciones fiscales sin la intención de atenuar necesidades de financiamiento inmediato e imprevisto, el alcance y la ambición original de las reformas se han visto seriamente reducidas en el contenido final de las normas y en los resultados a cinco o diez años de estas. Entretanto, las contingencias potenciales de tener un sistema de recaudo ineficiente y desactualizado se acumulan y se reflejan en el aumento del déficit fiscal, con el que las reformas endógenas al producto interno bruto combaten en períodos cortos. A pesar de estos esfuerzos, el aumento del déficit aún dentro de la regla fiscal es a lo menos alarmante, sobre todo teniendo en cuenta del número de tributos "provisionales" con los que cuenta el ordenamiento y cuyas vigencias, al menos en el papel, son finitas. Ejemplo de ello 
son el impuesto al patrimonio luego convertido en el impuesto a la riqueza, así como el gravamen a los movimientos financieros.

En un plano paralelo, la eficacia simbólica de la normativa tributaria, encaminada a aminorar los malos resultados en eficacia instrumental, impide que el monitoreo posible por parte de la población se haga efectivo. En apariencia el legislador se mantiene activo con miras a corregir sus propias deficiencias, y el símbolo de la producción legislativa impide un diagnóstico más profundo del problema que, especialmente en el caso de los gastos tributarios, no se resuelve. En tanto se mantenga la producción legislativa en materia tributaria que ausculte la normatividad con la intención de aumentar el recaudo en el corto plazo, de forma reactiva y solo frente a incapacidades inminentes de financiación del gobierno, será difícil que la evidente necesidad de una reforma estructural exógena el producto interno bruto se materialice. La complejidad del ordenamiento actual, aunada a la inadecuación de las herramientas disponibles en cabeza del fisco para perseguir los abusos de la ley y evidenciarlos (la cláusula antiabuso aún no ha sido utilizada por la DIAN, a pesar de contar con casi tres años de vigencia) dificultan que una eventual iniciativa fuera del legislativo logre lo que reformas anteriores se han propuesto y no han conseguido. La visibilidad del problema es pobre y requiere iniciativa gubernamental o académica para contar con el impulso suficiente para ser aprobada completamente.

Las soluciones están, por lo tanto, en manos del legislativo, pero tanto la academia como los sectores del gobierno encargados de la política económica y fiscal han reconocido algunas de las problemáticas aquí evidenciadas con anterioridad. Los problemas que se han tornado estructurales requieren esfuerzos considerables del Congreso de la República, obviamente con una buena propuesta técnica gubernamental, que no solo incrementen la producción legislativa sino que reestructuren, depuren, organicen y sistematicen las instituciones tributarias existentes. A pesar de que el crecimiento del déficit fiscal y la ineptitud de nuestra normatividad para satisfacer las necesidades presupuestales del gobierno son problemas patentes que podrían abordarse con propuestas de otras instancias de la ciudadanía, en últimas, "en derecho las cosas se deshacen como se hacen".

\section{Referencias}

1. Ayala, J. (2006). Reforma tributaria estructural. Bogotá: Konrad Adenauer Stiftung / Pensamiento Siglo XXI.

2. Azuero, F., Guzmán, A. y Trujillo, M. (2011). Contratos de estabilidad jurídica en Colombia (cej): ¿información asimétrica, inconsistencia intertemporal o captura de la autoridad tributaria? En Galeras de la Administración, (31). Bogotá: Facultad de Administración, Universidad de los Andes.

3. Bravo Arteaga, J. R. (2009). Nociones fundamentales de derecho tributario. Bogotá: Temis. 
4. Brixi, H. V. (2004). Tax Expenditures Shedding Light on Government Spending Through the Tax System. Washington D. C.: World Bank Directions in Development 27583.

5. Cárdenas, M. y Mercer-Blackman, V. E. (2005). El sistema tributario colombiano: impacto sobre la eficiencia y la competitividad. Bogotá: Fedesarrollo/ Confecámaras.

6. Clavijo, S. (2005). Tributación, equidad y eficiencia en Colombia: Guía para salir de un sistema tributario amalgamado. Borradores de Economía, (325).

7. Echavarría, S. E. (2005). El impuesto a la renta presentó un recaudo del 4,16\% como porcentaje del pib para 1994. Medellín: Universidad de Medellín.

8. Fjeldstad, O.-H. (2006). Tax Evasion and Fiscal Corruption. Essays on Compliance and Tax Administrative Practices in East and South Africa. Bergen: Norwegian School of Economics and Business Administration.

9. Garay, J. (2004). Colombia: estructura industrial e internacionalización 1967-1996. Bogotá: Banco de la República.

10. García Villegas, M. (1993). La eficacia simbólica del derecho: examen de situaciones colombianas. Bogotá: Ediciones Uniandes.

11. Hamann, F., Lozano, I. y Mejía, L. (2011). Sobre el impacto macroeconómico de los be- neficios tributarios al capital. Borradores de Economía, (668).

12. Lewin, A. (2007). Historia de las reformas tributarias en Colombia. En E. Lozano, Fundamentos de la tributación. Bogotá: Ediciones Uniandes.

13. Lozano, E. (en prensa). Perspectivas jurídicas para la paz colombiana: Algunas consideraciones económicas pro igualdad. Buenos Aires: Editorial Libraria.

14. Lozano, E. y Mendoza, C. (2008). Hermenéutica tributaria. En E. Lozano Rodríguez, Fundamentos de la tributación. Bogotá: Ediciones Uniandes/ Editorial Temis.

15. Lozano, E. y Tamayo, D. (2014). Ética y tributación - Una primera aproximación. En Estudios interdisciplinarios de la tributación. Bogotá: Biblioteca Jurídica Uniandina/Editorial Temis.

16. Moller, L. C., Junquera-Varela, R. F., Jorratt, M., Biagini, C., Álvarez, D., Bussolo, M. ... Rueda Gómez, M. (2012). El gasto tributario en Colombia: una propuesta de evaluación integral y sistemática de este instrumento de política pública. Bogotá: Banco Mundial.

17. Organización para la Cooperación y el Desarrollo Económicos [ocde]. (2010). Tax expenditures in oecd Countries. París: oecd Publishing.

18. Organización para la Cooperación y el Desarrollo Económicos. (2015). Revenue Sta- 
tistics in Latin America and the Caribbean 1990-2013. París: oecd Publishing.

19. Parra, O. y Patiño, R. (2010). Evasión de impuestos nacionales en Colombia: 20012009. Revista Facultad de Ciencias Económicas: Investigación y Reflexión, 18(2).

20. Procolombia. (s.f). Zonas francas y otros incentivos en Colombia. Recuperado de: http://www.inviertaencolombia.com.co/zonas-francas-y-otros-incentivos.html

21. Roca, J. (2010). Evaluation of the Effectiveness and Efficiency of Tax Benefits. Washington D.C.: Inter-American Development Bank.
22. Romer, C. D., y Romer, D. H. (June 2010). The Macroeconomics Effects of Tax Changes: Estimates Based on a New Measure of Fiscal Shocks. American Economic Review, (100), 763-801.

23. Sánchez, F. y Espinosa, F. (2005). Impuestos y reformas tributarias en Colombia 19802003. Documentos cede.

24. Weisbach, D. A. (Edit.). (2008). Economics of Tax Law. USA: Elgar Publishing Inc. 